\title{
Anesthesia in Multiple Sclerosis
}

\author{
C. BAMFORD, W. SIBLEY and J. LAGUNA
}

SUMMARY: The effect of general anesthesia on 42 multiple sclerosis (MS) patients who underwent 88 episodes of general anesthesia was analyzed. One patient experienced a relapse after a procedure under general anesthesia, which is compatible with the natural history of the disease. A literature review revealed little information on this subject or on the use of particular anesthetic agents in MS. Our experience with spinal and local anesthesia is reported. In the evaluation of the former our limited data suggested that spinal anesthesia is less preferable than other alternatives in MS. Local anesthetics had a benign effect on the course of $M S$.

RESUME: Nous avons analysé l'effet de l'anesthésie générale sur l'évolution de la maladie chez 42 patients souffrant de Sclérose en Plaques et qui avaient subi 88 épisodes d'anesthésie générale. Un seul patient a souffert d'une rechute après une telle procédure, une incidence compatible avec l'histoire naturelle de la maladie. Une revue de la littérature a peu révélé à ce sujet, ou au sujet du choix d'un agent anesthésique particulier. Nous rapportons donc notre propre expérience avec l'anesthésie spinale et locale. Notre expérience limitée nous suggère que l'anesthésie spinale est moins préférable dans la Sclérose en Plaques. L'anesthésie locale n'a qu'un effet minime sur l'évolution de la maladie.

From the Department of Neurology, University of Arizona College of Medicine and Health Sciences Center, Tucson.

Reprint requests to Dr. C. R. Bamford, Department of Neurology, University of Arizona Health Sciences Center, 1501 N. Campbell Avenue, Tucson, Arizona 85724 . U.S.A.
Multiple Sclerosis (MS) is a disease characterized by relapses which occur randomly throughout the patient's disease course. The anesthesiologist who provides care to an MS patient should be concerned that he uses agents shown to have little effect on the course of the disease. We think it important to publish guidelines on the safest procedures. The physician should be aware that he may provide care to a patient prior to the natural occurrence of an MS relapse.

\section{METHODS}

The MS Clinic at the University of Arizona interviews 125 patients monthly. Twenty-five patients were excluded from the study due to inability to recall prior events.

The remaining 100 were questioned about their experiences with anesthesia during the time they had MS. Of these, 42 reported 88 general anesthetics. In 33, hospital records were available and operative and post-operative records were inspected to confirm the historical data.

Eight patients reported 12 episodes of spinal and caudal anesthesia. Ninety-eight patients admitted to multiple local anesthetics.

An association between anesthesia and deterioration of MS was considered significant if the deterioration had its onset within the month following the anesthetic. Continued worsening of a patient who was in the slowly progressive stage of MS prior to surgery was not considered significant unless the worsening occurred at an accelerated pace in the post-operative month.

\section{RESULTS}

General Anesthesia

A total of 42 patients underwent
88 episodes of general anesthesia (Table 1). One patient stated that she experienced an attack of MS in the month following anesthesia and surgery. One patient noted that she had progressive deterioration of MS prior to a pelvic procedure, and this deterioration continued postoperatively at an increased rate. In both cases the worsening was confirmed by their post-operative records.

\section{Case 1}

S. E. is a 32-year-old white American female who had the onset of dragging of the right leg at the age of 27 . When examined at this time she was noted to have a spastic monoparesis. A myelogram was performed, which was within normal limits. She spontaneously partially improved, but subsequently complained of urinary incontinence, weakness and stiffness of the right leg. At the age of 32 she underwent a laparoscopy and tubal ligatior. after receiving methohexital sodium $100 \mathrm{mg}$., succinylocholine, and d-tubocurarine. Less than one month later she noted marked accentuation of the right leg weakness, and noted the onset of numbness of the right leg to painful and light tactile stimuli. Over the following months she again partially recovered. On physical examination, she was noted to have normal cranial nerves, marked weakness of the right hip flexor and ankle extensor, hyperactive deep tendon retlexes, absent vibration sensation at both ankles, and impaired heel-shin and tandem gait tests.

\section{Case 2}

N. H. is a 50 -year-old wheelchair bound white American female who had the onset of weakness of the legs at the age of 44 . Shortly afterwards she complained of double vision. These symptoms resolved. At the age of 46 she developed severe weakness of the legs which again resolved, but from that time leg weakness began to progressively return. She was ambulatory prior to the repair of a cystocele and a panhysterectomy (atropine, demerol, atarax, sodium thiopentone, nitrous oxide, fluothane, and succinylcholine), however, one week later on attempting to ambulate she noted that her right leg was paralysed. On neurologic examination she was noted to have horizontal nystagmus, marked weakness and spasticity of the legs, hyperactive knee jerks, bilateral Babinski reflexes, and the ab- 
TABLE 1

47 Episodes of General Anesthesia in 33 Patients

\begin{tabular}{lcc}
\hline Type of Procedure & $\begin{array}{c}\text { No. of Procedures } \\
\text { Undergone }\end{array}$ & $\begin{array}{c}\text { No. of Procedures } \\
\text { Associated with Post- } \\
\text { Operative Deterioration }\end{array}$ \\
\hline Major Orthopedic & 3 & 0 \\
Minor Orthopedic & 2 & 0 \\
Major Gynecological & 6 & 0 \\
Minor Gynecological & 1 & 0 \\
Major Abdominal & 9 & 0 \\
Minor Abdominal & 3 & 1 \\
Minor Rectal & 2 & 0 \\
Major Urological & 2 & 0 \\
Minor Urological & 6 & 0 \\
Major Thoracic & 1 & 0 \\
Minor Thoracic & 1 & 0 \\
Mastectomy & 3 & 0 \\
Cataract Extraction & 1 & 0 \\
Plastic Surgical & 1 & 1 \\
Lumbar Laminectomy & 1 & 0 \\
Stereotaxic Campotomy & 1 & 0 \\
\hline
\end{tabular}

sence of sensation for vibratory stimuli applied to the ankles.

The anesthetic agents to which the 33 patients were exposed during the 47 general anesthetics were used in conventional dosages. The names of the agents, the number of exposures and the association with deterioration of MS have been recorded in Table 2. No complications of general anesthesia were identified during or immediately after each of the 47 procedures.

\section{Spinal and Caudal Anesthesia}

Three patients underwent spinal anesthesia during delivery. One of these noticed the deterioration of MS in the following month (Case 3). One patient underwent caudal anesthesia during each of three deliveries and experienced no post-partum deterioration. Four patients had spinal anesthesia for six minor operative procedures ( 3 TUR's, 1 D\&C, 2 plastic surgical) and these were tolerated well, except for one patient who developed a wound infection to which minor fluctuations in preexisting MS symptoms were attributed.
Seven patients had spinal anesthesia on nine separate occasions. One patient had a caudal anesthetic three

\section{Case 3}

J. C., a 48-year-old white American female, had the onset of weakness of the left leg at age 24. This improved the following year. She delivered a male infant under spinal anesthesia at the age of 29 . and in the following weeks noticed the onset of weakness of the left leg which caused repeated falling. This gradually resolved over the following months. $A$ second child was delivered under spinal anesthesia at the age of 32, and the patient noticed no deterioration of her MS symptoms in the following months. At the age of 36 she developed double vision, slurred speech and intermittent tingling. In 1977 neurologic examination showed bilateral internuclear ophthalmoplegia, slight weakness of the left hip flexor and ankle extensor, bilateral Babinski reflexes, and impaired coordination of all four extremities. The gait was mildly hemiparetic on the left.

\section{Local Anesthesia}

Ninety-eight patients admitted to having had multiple (usually more than 10) local anesthetics for minor operative and dental procedures during the time when they had MS. Four patients noticed deterioration times. of their MS in the month following a single anesthetic. These four patients had no complications of local anesthesia on other occasions. Five patients noted the development of unpleasant side effects of local anesthesia (light-headedness, transient weakness, etc.).

The dental records of 46 of the above patients were reviewed (Table 3). Two of these had deterioration of MS in the month following exposure to the two most commonly used anesthetics. The 46 patients received more than 150 local anesthetics.

\section{DISCUSSION \\ General Anesthesia}

Most authors have not attempted to differentiate between the effects of surgery and general anesthesia on the courses of MS.

McAlpine and Compston (1952) reported that in the three months following 36 operations, there was a total of nine relapses, giving a retrospectively determined relapse rate of one per patient year. This differs significantly from the baseline attack rate of .39 per patient year. Ridley and Schapira (1961) studied $40 \mathrm{MS}$ patients who had 57 operations under general anesthesia. During the post-operative month no acute relapses occurred. However, in eight patients the degree of disability was worse, in 47 there was no change in disability and in two there was improvement. These authors found little justification to avoid surgery when this was indicated on its own merits. This statement was endorsed by Miller (1961).

Keschner (1950) reported 31 major operative procedures experienced by patients with MS. Only one case was characterized by post-operative deterioration of MS. He also reported 31 minor operative procedures, four of which were followed by aggravation of MS. In his report, however, it was not clear whether the aggravation was a new relapse, progression of diability or minor fluctuations of symptoms. The length of the post-operative period was not clearly defined. Keschner concluded that operative procedures did not affect the course of 
MS, and he considered general anesthesia more favorable than spinal anesthesia.

Baskett and Armstrong (1970) reported four cases in which they considered an association existed between the use of specific anesthetic agents and deterioration of MS. We agree that relapses occurred in cases one and four. However, in case two the post-operative incontinence probably represented fluctuation in the symptoms of a preexisting myelopathy. In case three, postoperative drowsiness and confusion in a patient with far advanced MS was probably due to the cumulative effect of metabolic problems superimposed on underlying brain damage.

In our series of 33 patients, two patients noticed a deterioration during the post-operative month. One patient (S.E.) developed an objectively confirmed relapse towards the end of the month following laparoscopy. She had received methohexital sodium, and nitrous oxide for this surgical procedure (Tables I \& II). The second patient noticed progressive leg weakness prior to undergoing a hysterectomy. This increased post-operatively. It is not clear whether the rate of deterioration increased, however. (Tables I \& II). Using retrospective historical data, only one out of 88 episodes of general anesthesia was associated with deterioration which had its onset in the post-operative month. This is an incidence of 0.14 relapses/patient year which is less than the expected incidence of spontaneous relapses. [retrospectively determined relapse rate for the Health Sciences Center MS Clinic $=0.27$ relapses $/$ patient year (Sibley et. al., In Press)].

Using only data confirmed by chart review, one attack occurred following 47 episodes of general anesthesia. This is an incidence of .26 attacks/patient year, which closely approximates the retrospective attack rate and is less than the prospective attack rate of $0.44 /$ patient year (Sibley et. al., In Press).

Spinal and Caudal Anesthesia

Schapira (1959) has stated that
TABLE 2

\begin{tabular}{|c|c|c|c|}
\hline Name of Anesthetic Agent & $\begin{array}{l}\text { No. of Episodes } \\
\text { of Exposure }\end{array}$ & $\begin{array}{l}\text { No. of Episodes of } \\
\text { Exposure Associated } \\
\text { with Relapses }\end{array}$ & $\begin{array}{l}\text { No. of Episodes of Exposure } \\
\text { Associated with Increased } \\
\text { Progression of Disability }\end{array}$ \\
\hline 1. dofopme & 35 & 0 & 1 \\
\hline 2. meper udue hydiochlonde & 23 & 0 & 1 \\
\hline 3. hydioxyzure & 13 & 0 & 1 \\
\hline 4. fentanyl & 16 & 0 & 1 \\
\hline 5. Hoperidol & 11 & 0 & 0 \\
\hline 6. didzepam & 7 & 0 & 0 \\
\hline 7. morphure sulphate & 3 & 0 & 0 \\
\hline 8. scopolamme & 1 & 0 & 0 \\
\hline 9. sodium thiopentone & 39 & 0 & 1 \\
\hline 10. succinyl cholıne & 26 & 0 & 1 \\
\hline 11. d-tubocurarne & 11 & 1 & 0 \\
\hline 12. pancusonium tromide & 7 & 0 & 0 \\
\hline 13. methohexital soclium & 5 & 1 & 0 \\
\hline 14. mitrous oxide & 40 & 1 & 1 \\
\hline 15. halothane & 18 & 0 & 1 \\
\hline 16. cyclopropane & 1 & 0 & 0 \\
\hline 17. methoxyfluorante & 1 & 0 & 0 \\
\hline
\end{tabular}

lumbar puncture has little effect on the course of MS. Thus, any untoward effect of spinal and/or caudal anesthesia would have to be due to the instillation of local anesthetic into the subarachnoid space. Keschner (1950) reported a single case of MS aggravated by spinal anesthesia. $\mathrm{He}$ concluded that spinal anesthesia should be avoided in MS. Similar sentiments had been expressed by Critchley (1937) and Hammes (1943).

A more recent and valuable contribution by Stenuit and Marchand (1968) reviewed the records of patients who had undergone spinal anesthesia from 1961 to 1966 . They identified 29 cases who had complications. Among these 29 cases were 19 with multiple sclerosis. Two of the 19 cases had a definite aggravation of MS symptoms. The remaining 17 cases had significant problems which were not directly attributable to an MS relapse.

In our limited study there was a $10 \%$ incidence of aggravation of MS symptoms in the post spinalanesthetic month. This is higher than the expected relapse rate, but should be interpreted with caution because of the small number of patients. We do not encourage the use of spinal anesthesia in multiple sclerosis or in any patient who has a
TABLE 3

A total of 46 patients who had their dental records reviewed had exposures to the local anesthetics listed below.

\begin{tabular}{|c|c|c|c|c|c|c|}
\hline & \multicolumn{5}{|c|}{ Name of Agent } & \multirow[b]{2}{*}{ Total } \\
\hline & Lidocaine & Mepivacaine & Propoxycaine & Procaine & Prilocaine & \\
\hline $\begin{array}{l}\text { No. of patients who had an } \\
\text { MS attack in the post. } \\
\text { anesthetic month }\end{array}$ & 1 & 1 & 0 & 0 & 0 & 2 \\
\hline $\begin{array}{l}\text { No. of exposures to local } \\
\text { anesthetic associated with } \\
\text { an attack of MS }\end{array}$ & 1 & 1 & 0 & 0 & 0 & 2 \\
\hline $\begin{array}{l}\text { No. of patients who did not } \\
\text { have an MS attack in the } \\
\text { post anesthetic month }\end{array}$ & 39 & 11 & 3 & 1 & 1 & 55 \\
\hline $\begin{array}{l}\text { No of exposures not } \\
\text { associated with an } \\
\text { MS attack }\end{array}$ & $105+4 M$ & $29+3 M$ & $5+M$ & $M$ & 1 & $140+9 M$ \\
\hline
\end{tabular}

$M=$ multiple exposures by a single patient. 
preexisting myelopathy or neurologic disease, if there is a reasonably safe and convenient alternative. We base this opinion on a review of the medical literature, rather than on our limited experience.

\section{Local Anesthesia}

A total of 98 patients probably received more than 1,000 local anesthetics while they had MS. Four patients had aggravation of MS symptomatology in the post anesthetic month, an incidence which is quite consistent with the coincidental occurrence of relapses characteristic of the natural history of the disease. The evaluation of objective data alone (Table 3 ) produced similar results.

\section{CONCLUSION}

We found no evidence to suggest that general anesthesia precipitated relapses or increased the rate of progression of disability. We caution that temporary fluctuations of MS symptoms can occur postoperatively in MS patients due to the known effects of fever and metabolic imbalance upon nerve transmission. These fluctuations should not be unjustly attributed to general anesthesia alone, nor should they be confused with MS relapses or progression of disability. Spinal anesthesia should probably be avoided in MS, until the safety of the procedure has been convincingly established by other investigators. Local anesthesia is well tolerated by MS patients.

\section{REFERENCES}

MCALPINE, D. and COMPSTON, N. (1952). Some Aspects of the Natural History of Disseminated Sclerosis. Quarterly Journal of Medicine, New Series XXI, No. 82, pp. 135-167.

RIDLEY A. and SCHAPIRA, K. (1961). Influence of Surgical Procedures on the
Course of Multiple Sclerosis. Neurology, V II, pp. 81-92.

MILLER, H. (1961). Aetiological Factors in Disseminated Sclerosis. Proceedings of the Royal Society of Medicine, V 54, pp. 7-10.

KESCHNER, M. (1950). The Effects of Injuries and Illness on the Course of Multiple Sclerosis. Res. Publ. Assoc. Nerv. and Ment. Diseases. 28: 533-547.

BASKETT, P. and ARMSTRONG, R. (1970). Anesthetic Problems in Multiple Sclerosis. Are Certain Agents Contraindicated? Anesthesia, V 25, No. 3, pp. 397-401.

SIBLEY, W., BAMFORD, C. and LAGUNA, $J$. The Frequency of Relapse and the Disability of Multiple Sclerosis in the S.W. U.S.A. In Press.

SCHAPIRA, K. (1959). Is Lumbar Puncture Harmful in Multiple Sclerosis? J. Neuro. Neurosurg. Psychiat., V 22, p. 238.

CRITCHLEY, M. (1937). Discussion on the Neurological Sequelae of Spinal Anesthesia. Proc. R. Soc. M. Lond. V. 30, pp. 1007-1012.

HAMMES, E. (1943). Neurological Complications Associated With Spinal Anesthesia. Minn. Med., V 36, pp. 339-345.

STENUIT, J. and MARCHAND, P. (1968). Les Sequelles de Rachi-Anesthesie. Acta. Neurol. Belg. V 68 (8), 626-635. 